\title{
Enhancement of malignant properties of human glioma cells by ganglioside GD3/GD2
}

\author{
TAIJI IWASAWA ${ }^{1}$, PU ZHANG $^{1,2}$, YUKI OHKAWA ${ }^{2}$, HIROYUKI MOMOTA $^{3}$, TOSHIHIKO WAKABAYASHI $^{3}$, \\ YUHSUKE OHMI $^{1}$, ROBIUL H. BHUIYAN ${ }^{2}$, KEIKO FURUKAWA ${ }^{2}$ and KOICHI FURUKAWA ${ }^{1,2}$ \\ ${ }^{1}$ Department of Biochemistry II, Nagoya University Graduate School of Medicine, Nagoya 466-8550; \\ ${ }^{2}$ Department of Biomedical Sciences, Chubu University College of Life and Health Sciences, Kasugai, Aichi 487-8501; \\ ${ }^{3}$ Department of Neurosurgery, Nagoya University Graduate School of Medicine, Nagoya 466-8550, Japan
}

Received October 9, 2017; Accepted January 19, 2018

DOI: $10.3892 /$ ijo.2018.4266

\begin{abstract}
Sialic acid-containing glycosphingolipids, gangliosides, are considered as cancer associated antigens in neuro-ectoderm-derived tumors such as melanomas and neuroblastomas. In particular, gangliosides GD3 and GD2 are expressed in human gliomas. It has been reported that their expression levels increase along with increased malignant properties. However, the implication of GD3/GD2 in human glioma cells has never been clarified, at least to the best of our knowledge. In this study, we introduced the cDNA of GD3 synthase (GD3S)(ST8SIA1) into a glioma cell line, U-251MG, that expresses neither GD3 nor GD2, thereby establishing transfectant cells U-251MG-GD3S(+) expressing high levels of GD3 and GD2 on the cell surface. In these U-251MG-GD3S(+) cell lines, signaling molecules such as Erk1/2, Akt, p130Cas, paxillin and focal adhesion kinase were activated, leading to the enhancement of invasion activity and motility. It was then demonstrated that the U-251MG-GD3S(+) cells could proliferate under culture conditions with low or no serum concentrations without undergoing cell cycle arrest by escaping the accumulation of p16 and p21. All these results suggested that GD3 and GD2 highly expressed in gliomas confer increased invasion and mobility, cell growth abilities under low serum conditions, and increased ratios of the $\mathrm{S}-\mathrm{G} 2 / \mathrm{M}$ phase in the cell cycle.
\end{abstract}

Correspondence to: Professor Koichi Furukawa, Department of Biomedical Sciences, Chubu University College of Life and Health Sciences, 1200 Matsumoto, Kasugai, Aichi 487-8501, Japan

E-mail: koichi@isc.chubu.ac.jp

Abbreviations: GD3S, GD3 synthase; mAb, monoclonal antibody; DMEM, Dulbecco's modified Eagle's medium; FCS, fetal calf serum; RT-qPCR, reverse transcription-quantitative PCR; FAK, focal adhesion kinase; RTK, receptor tyrosine kinase

Key words: glioma, ganglioside, sialyltransferase, cell growth, invasion, cell cycle

\section{Introduction}

Brain tissues consist of neurons and glial cells, including astrocytes, oligodendrocytes, microglia and ependymal cells. They differentiate under the control of various transcription factors (1). Gliomas generally occur from glial cells or their precursor cells, and consist of various subtypes with different histologies and natures (2-4). However, gliomas generally exhibit a high invasive activity, and expand outward by infiltrating into normal bain tissues (5). They are actually resistant to chemotherapy and radiation therapy, and the presence of brain blood barrier hampers the effects of various anticancer reagents. On the other hand, surgical resection is not so efficient, since neural tissues have no regenerative capacity. Thus, there are no radical therapies to eradicate gliomas, and thus patients with the disease have a very poor prognosis. In particular, patients with glioblastomas have the worst prognosis, i.e., the 1 -year survival rate is $51.6 \%$ and the 5 -year survival rate is $7.8 \%$ (6).

Sialic acid-containing glycosphingolipids, gangliosides, have been reported to be expressed at very high levels in neural tissues (7), and play important roles in the development and functions of the central nervous system (8). In particular, glycosphingolipid structures change during brain development and among various anatomical sites, which strongly suggests that individual gangliosides play roles depending on the polymorphic carbohydrate structures (9). During the early stages of embryogenesis, simple gangliosides, such as GM3 and GD3 are major structures. On the other hand, more complex gangliosides (GM1, GD1a, GD1b and GT1b) are mainly expressed during the later stages of brain formation, such as neurite extension and synaptogenesis (10).

Some gangliosides have been reported to be tumorassociated antigens $(11,12)$. For example, a number of neuro-ectoderm-derived cancers, such as melanomas (12) and neuroblastomas $(13,14)$ have been reported to characteristically express GD3 and GD2, respectively. Recently, a number of studies have demonstrated that other human cancers also express GD3 and GD2, such as GD3 in childhood T cell lymphoblastic malignancies and human leukocytes and leukemia cells $(15,16)$, as well as GD2 in other human cancers, i.e., neuroblastomas $(13,14)$, small cell lung carcinomas $(17,18)$, 
osteosarcomas (19,20), breast cancers (21) and human lymphotropic type I virus-infected T cells (22).

As for gliomas, there are some studies on the expression of gangliosides with relatively short chains (23-29). Although there have been some reports on GD3 and/or GD2 expression in gliomas, and on the degree of malignancy increasing along with the elevated expression of these gangliosides (27), there have been no studies to date investigating the roles of gangliosides in the malignant properties of human gliomas, at least to the best of our knowledge.

In this study, we aimed to determine the mechanisms through which gangliosides are involved in the malignant properties of gliomas, and to identify the molecules involved in the signaling pathways mediated by glioma-associated gangliosides. The nomenclature of gangliosides was based on the study by Svennerholm (30).

\section{Materials and methods}

Immunohistochemistry. Brain tumor samples were obtained for use in the experiments after obtaining informed consent. This study was performed in accordance with the code of Ethics of the World Medical Association, and approved by the Ethics Committee of Nagoya University Graduate School of Medicine, Nagoya, Japan. The brain tumors were embedded in OCT compound (Tissue-TEK ${ }^{\mathrm{TM}}$; Sakura Finetek Japan, Tokyo, Japan) immediately after surgical resection, and frozen sections were prepared using a cryostat ULTRACUT $\mathrm{S}^{\mathrm{TM}}$ (Reichert, Leica, Wien, Austria) with $7 \mu \mathrm{m}$ thickness, and then mounted onto MAS-coated slide glasses. After blocking with $10 \%$ goat serum in phosphate-buffered saline (PBS) at room temperature for $1 \mathrm{~h}$, staining was performed using monoclonal antibodies (mAbs) reactive with individual gangliosides. Anti-GD3 antibody (R24; mouse IgG3) was provided by L.J. Old at Sloan-Kettering Cancer Center, and anti-GD2 antibody (220-51; mouse IgG1) was as previously described (31). These mAbs were used at a 1:200 dilution of ascites. Reactions with these primary antibodies were carried out overnight at $4^{\circ} \mathrm{C}$, and the glass slides were washed with PBS 3 times, followed by incubation with the secondary antibody Alexa Fluor 555-labeled goat anti-mouse IgG (A21422; Invitrogen, Carlsbad, CA, USA) (1:500 dilution) at room temperature for $1 \mathrm{~h}$. After washing with PBS 3 times, ganglioside expression was examined under a confocal microscope FV-100-D (Olympus, Tokyo, Japan).

Cell culture. The cells were cultured in Dulbecco's modified Eagle's medium (DMEM) containing 10\% fetal calf serum (FCS), $0.16 \% \mathrm{NaHCO}_{3}, 2 \mathrm{mM}$ L-glutamine, $96 \mathrm{U} / \mathrm{ml}$ penicillin $\mathrm{G}, 72 \mathrm{U} / \mathrm{ml}$ streptomycin at $37^{\circ} \mathrm{C}$ under $5 \% \mathrm{CO}_{2}$. The cell lines used in this study were the following: Human glioma cell lines, U-251MG (from JCRB Cell Bank, Osaka, Japan), T-98G, U-87MG (both from ATCC, Manassas, VA, USA), and LN319 (from Y. Kato at Tohoku University, Sendai, Japan). It should be noted that the U-87MG cell line is not the original glioblastoma cell line established in 1968 at the University of Uppsala as previously described (32), but is most probably a glioblastoma cell line. The LN319 cell line is an anaplastic astrocytoma (mixed astrocytoma type), and has been shown to be a derivative of the LN-992 cell line (33). Since these issues are unlikely to affect the outcomes of our study, we decided to include these results from these problematic cell lines. Details can be seen at the following website from the International Cell Line Authentification Committee (ICLAC), the Database of Cross-Contaminated or Misidentified Cell Lines (http://iclac.org/databases/crosscontaminations/). Further information for the U87MG cell line can be found at http://web.expasy.org/ cellosaurus/CVCL_0022, and for the LN319 cell line at https://web.expasy. org/cellosaurus/CVCL_3958.

Flow cytometry. Following trypsinization of the cells in the dishes, the cells were washed with PBS $\left(\mathrm{Ca}^{++}, \mathrm{Mg}^{++}\right.$free) termed PBS(-) at $4^{\circ} \mathrm{C}$, then were resuspended in PBS(-) with $1 \%$ FCS. Using $\sim 5.0 \times 10^{4}$ to $1.0 \times 10^{5}$ cells, the primary antibody reaction was performed at $4^{\circ} \mathrm{C}$ for $1 \mathrm{~h}$ using mAbs $\mathrm{R} 24$ or 220-51 as described above, and the cells were then washed with PBS(-) 3 times. Subsequently, FITC-labeled secondary antibodies (goat anti-mouse IgG) (AS-28175-05; AnaSpec, Fremont, CA, USA) (1:200 dilution) were added to the cells, followed by incubation at $4^{\circ} \mathrm{C}$ for $1 \mathrm{~h}$. After washing with PBS(-), the labeled cells were analyzed using a FACSCalibur ${ }^{\mathrm{TM}}$ flow cytometer (BD Biosciences, Franklin Lakes, NJ, USA).

Reverse transcription-quantitative (real-time) PCR (RT-qPCR). Total RNA was extracted from the cells using TRIzol ${ }^{\mathrm{TM}}$ reagent (Invitrogen) according to the manufacturer's instructions. Using extracted total RNA, reverse transcription was performed using M-MLV RT ${ }^{\mathrm{TM}}$ (Invitrogen) according to the manufacturer's instructions. The final products, cDNAs were applied used in the DNA Engine Opticon2 ${ }^{\mathrm{TM}}$ system (MJ Research, Waltham, MA, USA) to quantify the gene expression levels. The primer sequences used were as follows: GD3 synthase (ST8SIA1) sense, 5'-ttcaacctctctcttccaca-3' and antisense, 5'-tcttcttcagaatcccacc att-3'; and $\beta$-actin (ACTINB) sense, 5'-acccactcctccacttgac-3' and antisense, 5'-cetgttgctgtagcccaaattcg -3 '.

Generation of transfectant cell lines of GD3 synthase cDNA. The U-251MG cells were transfected with an expression vector, pMIKneo-GD3S (34) using Lipofectamine $2000^{\mathrm{TM}}$ (Invitorgen) and OPTI-MEM ${ }^{\mathrm{TM}}$ (Gibco-BRL, Gaithersburg, MD,USA) followed by selection with G418 (500 $\mu \mathrm{g} / \mathrm{ml})$. Finally, G418-resistant GD3-positive cells were applied for limiting dilution to establish monoclonal cell lines. The synthetic pathway of gangliosides is shown in Fig. 1A.

Invasion assay. The cell invasive activity was examined using the Boyden-chamber method as previously described (35). The cells were plated in the upper chamber in DMEM, and the chamber was placed in $2 \mathrm{ml}$ of $0.1 \%$ FCS-containing DMEM in a 6-well plate. After $24 \mathrm{~h}$, the numbers of cells that had migrated to the reverse side of the chamber were counted after being fixed and stained with Giemsa (Wako, Osaka, Japan). The counting of the cell numbers was carried out randomly selecting 9 vision fields with no overlapping under an inverted research microscope (Olympus IX73; Olympus, Tokyo, Japan)

MTT assay. The cells $\left(3.0-5.0 \times 10^{3}\right)$ were plated in 96-well plates, and incubated for the appropriate amount of time (12-24 h). Subsequently, MTT solution $(5 \mathrm{mg} / \mathrm{ml})$ was added 


\section{A}

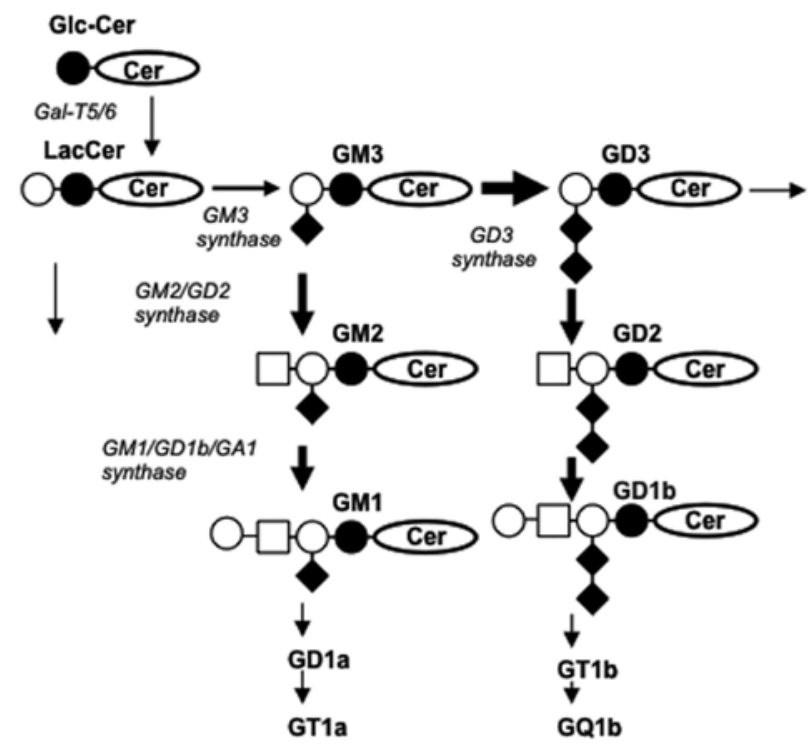

Cer : ceramide;

: glucose $\bigcirc$ : galactose ;

$\mathrm{N}$-acetylgalactosamine;

: sialic acid

B

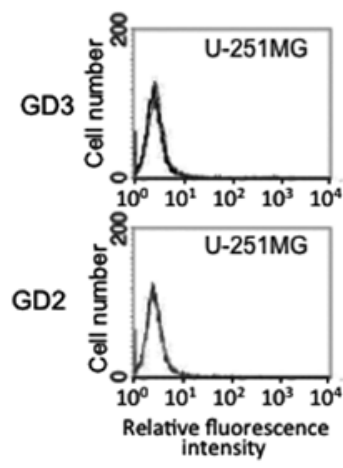

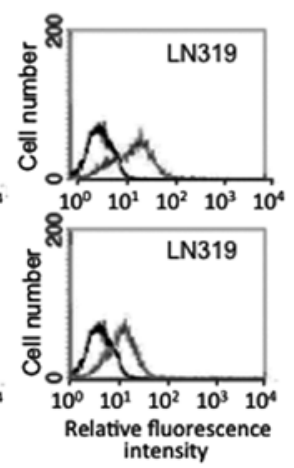

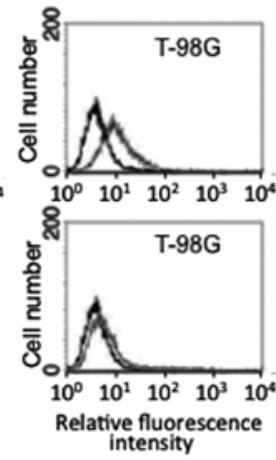

Figure 1. Expression of GD3/GD2 in human gliomas. (A) Synthetic pathway of gangliosides. ST8SIA1 (GD3 synthase, GD3S) is a key enzyme for the synthesis of b-series gangliosides, such as GD3/GD2. (B) Expression of GD2/GD3 on the cell surface in cultured glioma cell lines. Using the U-251MG, T98, LN319 and U-87MG cell lines, the surface expression of GD2/GD3 was analyzed by flow cytometry.

(20 $\mu \mathrm{l} /$ well), followed by incubation for $3 \mathrm{~h}$ at $37^{\circ} \mathrm{C}$ in a $5 \%$ incubator. Acidic isopropyl alcohol (150 $\mu \mathrm{l} /$ well) was added, and the cell membranes were destroyed by rigorous pipetting. Subsequently, $100 \mu \mathrm{l}$ of supernatant were transferred from each well to another 96-well plate, and the absorption was measured using an EIA reader at $590 \mathrm{~nm}$ (background: $620 \mathrm{~nm}$ ). The ratio of OD to the standard one was calculated, and plotted by the function of time.

Western blot analysis. Cell lysates were prepared by scraping the cells following the addition of lysis buffer to the dishes on ice, and the collected lysates were treated by sonication at $4^{\circ} \mathrm{C}$, then centrifuged at $20,630 \mathrm{x}$ g at $4^{\circ} \mathrm{C}$. The supernatants were used as cell lysates.

To prepare the fraction of lysates, trypsinized cells were collected and resuspended in buffer A [400 mM Tris- $\mathrm{HCl}$ (pH 7.4), $10 \mathrm{mM} \mathrm{NaCl}, 1 \mathrm{mM}$ EDTA, 0.5\% DTT, $1 \mathrm{mM}$ sodium orthovanadate, $1 \mathrm{mM} \mathrm{NaF}, 100 \mathrm{nM}$ Okadaic acid and $1 \mathrm{X}$ proteinase inhibitor mixture (Calbiochem, San Diego, CA, USA)]. These cells were gently treated with a syringe with $23 \mathrm{G}$ ca 10 times to destroy the cell membrane, and centrifuged at $1,000 \mathrm{x} \mathrm{g}$ for $10 \mathrm{~min}$ at $4^{\circ} \mathrm{C}$. The resulting supernatant was used as a cytoplasmic fraction. When the trypsinized cells were treated in buffer B [400 mM Tris- $\mathrm{HCl}(\mathrm{pH} 7.4), 150 \mathrm{mM}$ $\mathrm{NaCl}, 1 \mathrm{mM}$ EDTA, $0.2 \%$ Triton X-100, 0.5\% DTT, $1 \mathrm{mM}$ sodium orthovanadate, $1 \mathrm{mM} \mathrm{NaF}, 100 \mathrm{nM}$ Okadaic acid, and $1 \mathrm{X}$ proteinase inhibitor mixture], the lysates were vortexed 5 times $\left(1 \mathrm{~min}\right.$ each), and left for $10 \mathrm{~min}$ at $4^{\circ} \mathrm{C}$. Finally, the lysates were centrifuged at $16,000 \mathrm{x}$ g for $25 \mathrm{~min}$ at $4^{\circ} \mathrm{C}$, and the supernatant was used as solubilized proteins.

These lysates were treated with a 4 X SDS sample buffer [125 mM Tris- $\mathrm{HCl}$ (pH 6.8), 4\% SDS, 20\% glycerol, bromphenol blue (BPB) and 2\% 2-mercaptoethanol] and boiled for $5 \mathrm{~min}$. The proteins were then separated by SDS-PAGE, and blotted onto PVDF membranes (Immobilon-PT ${ }^{\mathrm{TM}}$; Merck Millipore, Tokyo, Japan) under wet condition for $240 \mathrm{~min}$ at $80 \mathrm{~V}$. After blotting, the PVDF membranes were soaked in PBST buffer [20 mM Tris- $\mathrm{HCl}$ (pH 7.5), $140 \mathrm{mM} \mathrm{NaCl}$ and $0.05 \%$ Tween-20], containing 5\% skim milk for $1 \mathrm{~h}$ at room temperature. The reaction with the primary antibody was performed at $4^{\circ} \mathrm{C}$ overnight. The membranes were then washed with PBST buffer 4 times, and the reaction with the secondary antibody was carried out for $1 \mathrm{~h}$ at room temperature. After washing, antibody binding was detected using $\mathrm{ECL}^{\mathrm{TM}}$ (GE Healthcare 
Japan, Tokyo, Japan). Antibodies used in western blotting were as follows: anti-focal adhesion kinase (FAK) antibody (SC558, rabbit $\operatorname{IgG}, 1: 1,000)$, anti-p130Cas (SC860, rabbit IgG, 1:1,000) purchased from Santa Cruz Biotechnology (Santa Cruz, CA, USA), anti-phospho-FAK (Tyr577, 3281, rabbit IgG, 1:1,000), anti-phospho-p130Cas (Tyr410, 4011S, rabbit IgG, 1:1,000), anti-paxillin antibody (total paxillin, 2542S, rabbit $\mathrm{IgG}$, 1:1,000; Tyr118, 2541, rabbit $\operatorname{IgG}, 1: 1,000)$, anti-phospho-p38 antibody (9211S, rabbit $\mathrm{IgG}, 1: 1,000)$, anti-p38 antibody (9212S, rabbit IgG, 1:1,000), anti-phospho-SAPK/JNK antibody (9251S, rabbit IgG, 1:1,000), anti-SAPK/JNK antibody $(9252 \mathrm{~S}$, rabbit IgG, 1:1,000), anti-p16 antibody (4824, mouse IgG, 1:1,000), anti-p21 antibody (2946S, mouse IgG, 1:1,000), anti-phospho-p53 (Ser20) antibody (9287, rabbit IgG, 1:500), anti-p53 antibody (9282S, rabbit IgG, 1:1,000), anti-phospho-Erk1/2 antibody (9101S, rabbit IgG, 1:1,000), anti-Erk1/2 antibody (9102S, IgG, 1:1,000), anti-phospho-Akt antibody (Thr308, 9275S, rabbit IgG, 1:1,000; Ser473, 9271S, rabbit IgG, 1:1,000) and anti-Akt antibody $(9272 \mathrm{~S}$, rabbit IgG, 1:1,000), anti-total mTOR (45175, mouse IgG, 1:1,000) and anti-phospho-mTOR (29715, rabbit IgG, 1:1,000) (all purchased from Cell Signaling Technology, Danvers, MA, USA). Anti-phospho-paxillin (Tyr31, 44-720G, rabbit IgG, 1:1,000) was purchased from Invitrogen. As the secondary antibodies, HRP-labeled anti-mouse IgG (NA931, 1:500) and HRP-labeled anti-rabbit IgG (NA934, 1:500) antibodies were purchased from GE Healthcare.

Analysis of apoptosis. Following trypsinization, the cells were treated with FITC-labeled Annexin V and propiodium iodide (PI) and incubated on ice for $30 \mathrm{~min}$, and then examined using a FACSCalibur ${ }^{\mathrm{TM}}$ flow cytometer (BD Biosciences) to obtain the 2-D staining pattern of FITC and PI as previously described (36).

Cell cycle analysis. Following detachment of the cells by trypsinization, 1 mM EDTA, $0.2 \%$ Triton X-100, $50 \mu \mathrm{g} / \mathrm{ml}$ RNase were added followed by incubation for $30 \mathrm{~min}$. After staining the DNA with PI, the fluorescence intensity of PI was measured using a FACSCalibur ${ }^{\mathrm{TM}}$ flow cytometer (BD Biosciences), and the cell cycle was analyzed using ModFiT LT ${ }^{\mathrm{TM}}$ software (Verity Software House, Topsham, ME, USA).

Real-time cell electron sensoring (RT-CES). The cells (1.0x10 $)$ were plated in the well of a RT-CES ${ }^{\mathrm{TM}} 16 \mathrm{x}$ E-plate (ACEA Biosciences, Inc; San Diego, CA, USA), and the cell index was measured according to the attached protocol provided by the company.

Statistical analysis. Data are presented as the means \pm SD. The data were analyzed by one-way ANOVA with the Tukey-Kramer post hoc test, or by two-way ANOVA with the Bonferroni post-hoc test except for Fig. 6 (Student's t-test), and as indicated in the individual figure legends.

\section{Results}

GD3/GD2 are definitely expressed as shown by the immunohistochemical staining of glioma tissues. Frozen sections of primary brain tumor tissues were applied for immunohistochemistry using anti-GD3 and anti-GD2 antibodies (data not shown). The definite expression of GD3 and GD2 in brain tumors was observed.

GD2/GD3 expression is found on the cell surface of glioma cells. Using the U-251MG, T-98G, LN319 and U-87MG cell lines, the surface expression of GD2/GD3 was analyzed by flow cytometry (Fig. 1B). Although the U-251MG cells did not express either GD3 or GD2, the T-98G cells expressed GD3, and the LN319 and U-87MG cells expressed both GD3 and GD2.

mRNA expression of GD3 synthase in cultured glioma cell lines. Using 4 glioma lines, U-251MG, T-98G, LN319 and U-87MG, the mRNA expression levels of the GD3 synthase gene were examined by RT-qPCR. The U-87MG cells exhibited high levels of GD3 synthase mRNA, while the U-251MG, T-98G and LN319 cells exhibited low expression levels (data not shown). Since the U-251MG cells repeatedly expressed almost no GD3 synthase gene corresponding with no expression of GD3 or GD2 (Fig. 1B), this cell line was deemed suitable for the transfection of GD3 synthase cDNA and the generation of a stable transfectant cell line to be used for the analysis of phenotypic changes and the functions of newly expressed gangliosides. Thus, the U-251MG cells were used for the remodeling of gangliosides hereafter.

Generation of stable transfectant cells of GD3 synthase cDNA using the U-251MG cells. Three clones each of U-251MG cells expressing GD3 [GD3(+)] and not expressing GD3 [GD3(-)] were generated by transfection with the expression vector, pMIKneo-GD3S suing Lipofectamine ${ }^{\mathrm{TM}}$ and subsequent limiting dilution. GD3(+) clones were designated as GT16, GT18 and GT29 [GD3(+) cells], while transfectants with the vector alone were designated as CV1, CV3 and CV5 [GD3(-) cells]. The cell surface expression of GD3/GD2 on these transfectant cells was analyzed by flow cytometry (Fig. 2A). All the GT16, GT18 and GT29 clones repeatedly exhibited a high expression of GD3/GD2. However, the expression of GD2 was stronger than that of GD3 in all GD3(+) cells, exhibiting similar patterns as observed in the immunohistochemistry of primary brain tumors.

The mRNA expression of GD3 synthase in these cell lines was confirmed by RT-qPCR (Fig. 2B). The GT16, GT18 and GT29 clones had a strong expression, whereas CV1, CV3, and CV5 had no expression, as was expected.

Increased invasion and motility of GD3(+) cells. In order to examine effects of GD3/GD2 expression on the representative malignant properties, the cell invasive activity (Fig. 3A), cell adhesion (Fig. 3B) and cell growth (Fig. 3C) were analyzed. The cell invasion activity was analyzed by Boyden-chamber assay, showing that the GD3(+) cells had a greater invasion activity than the GD3(-) cells (Fig. 3A). Using RT-CES, cell adhesion and subsequent cell expansion were examined with the GD3(+) cells and GD3(-) cells, and the GD3(+) cells had a greater adhesion/expansion activity than the GD3(-) cells (Fig. 3B). We also compared the growth rates of these cells, resulting in the almost equivalent cell growth under regular culture conditions (Fig. 3C). 
A

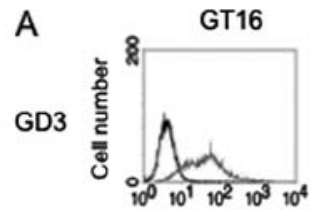
GD2

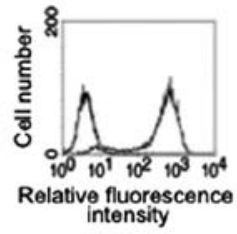

CV1

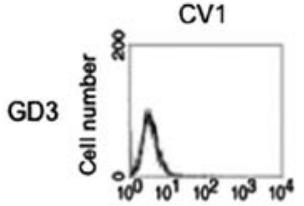

GD2

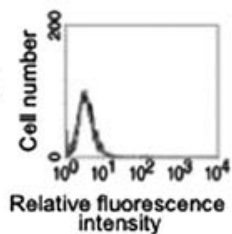

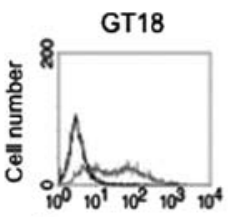
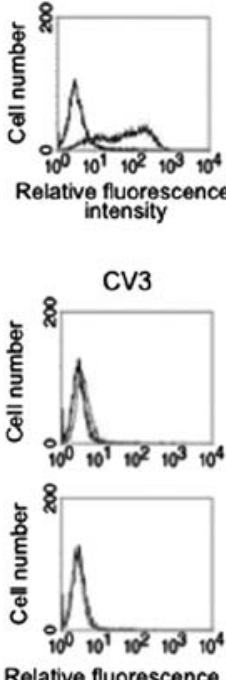

Relative fluorescence
intensity
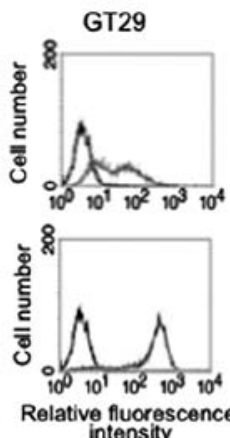

CV5
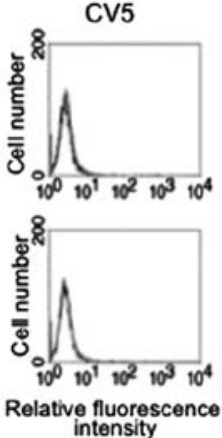

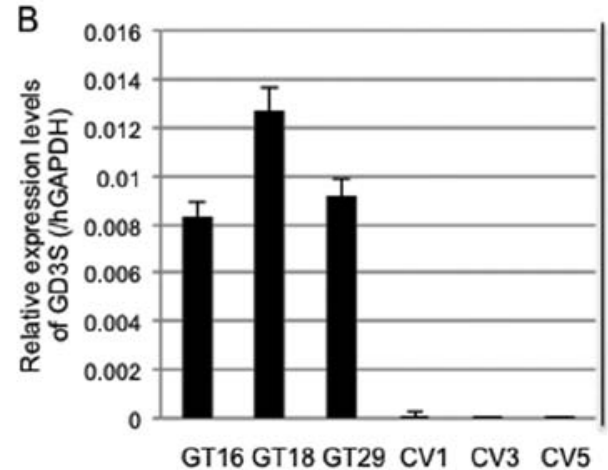

Figure 2. Generation of stable transfectant cells of GD3 synthase cDNA using U-251MG cells. Three clones each of U-251MG cells expressing GD3 and not expressing GD3 were generated by transfection with expression vector, pMIKneo-GD3S using Lipofectamine ${ }^{\mathrm{TM}}$ and subsequent limiting dilution. GD3(+) clones (GT16, GT18 and GT29) [GD3(+) cells], and transfectants with vector alone (CV1, CV3 and CV5) [GD3(-) cells] were established. (A) Cell surface expression of GD3/GD2 on these transfectant cells was analyzed by flow cytometry. (B) mRNA expression of GD3 synthase in these cell lines as analyzed by RT-qPCR. Three transfectants and 3 controls were compared, and transfectants exhibited an apparently higher expression levels than the controls, as was expected.
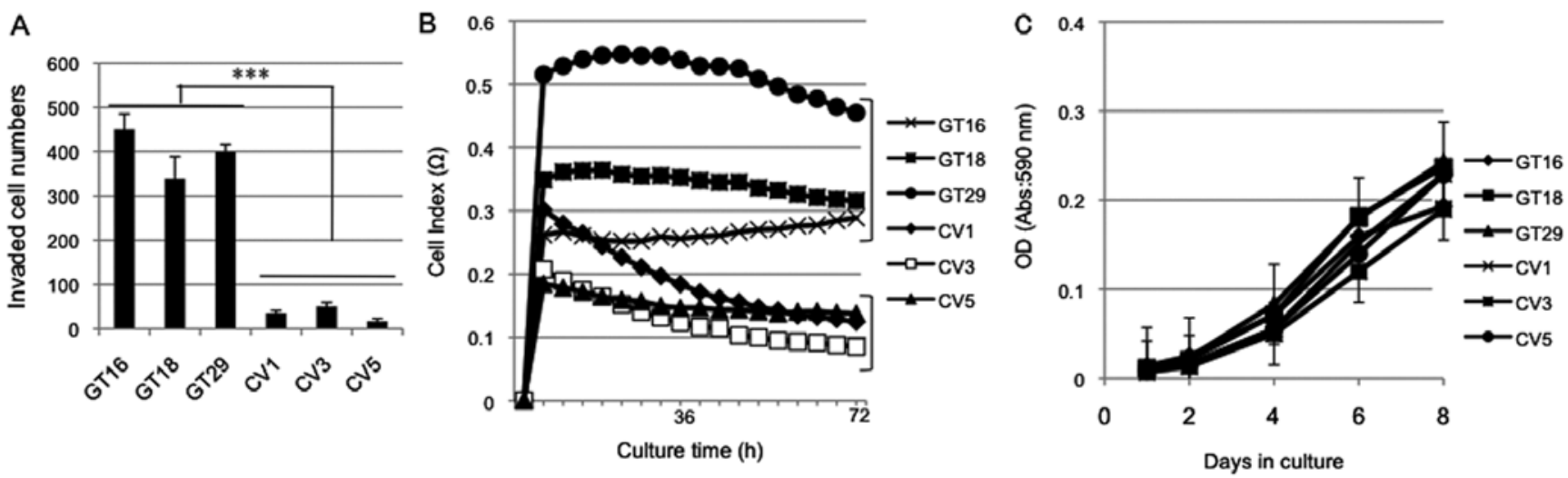

Figure 3. Invasion, motility, cell adhesion and cell growth in the transfectant cells. (A) Invasion activity was analyzed by Boyden-chamber assay. Cell numbers on the reverse side of membranes were counted following Giemsa staining, and presented in a graph. Transfectants $(\mathrm{n}=4$ each) and controls $(\mathrm{n}=4$ each) are presented as the means $\pm \mathrm{SD}$, and analyzed by one-way ANOVA with the Tukey-Kramer post hoc test. ${ }^{* * *} \mathrm{P}<0.001$. (B) Results of RT-CES analysis. Using the RT-CES system, cell adhesion and subsequent cell expansion were examined with GD3(+) cells and GD3(-) cells. (C) Comparison of cell growth rates as examined by MTT assay. Three each of transfectants and controls were examined by two-way ANOVA, exhibiting no statistical significance $(\mathrm{P}=0.274)$.

Subsequently, the phosphorylation levels of FAK, paxillin and $130 \mathrm{Cas}$, that have been reported to be involved in invasion and motility (35), were analyzed. Increased phosphorylation levels of FAK thr577, paxillin Tyr477 and p130Cas Tyr118 were observed in the GD3(+) cells at 12 and $24 \mathrm{~h}$ after plating (Fig. 4A). Furthermore, the activation levels of main signaling molecules involved in cell proliferation, i.e., Erk1/2 and Akt were analyzed. Consequently, western blot analysis of phosphorylated Erk1/2 and Akt revealed increased phosphorylation levels of both Erk1/2 and Akt thr308 in the GD3(+) transfectant lines (Fig. 4B). There were no apparent differences in the band intensities of either total mTOR or p-mTOR.

Cell growth under low-serum conditions. Since there was no significant difference in growth between the GD3/GD2-high U-87MG and GD3/GD2-negative U-251MGcells when cultured under regular conditions containing 10\% FCS (Fig. 5A, left panel), we compared the growth of these cells cultured under serum-free conditions. Consequently, the U-87MG cells cultured in serum-free conditions exhibited rapid growth 

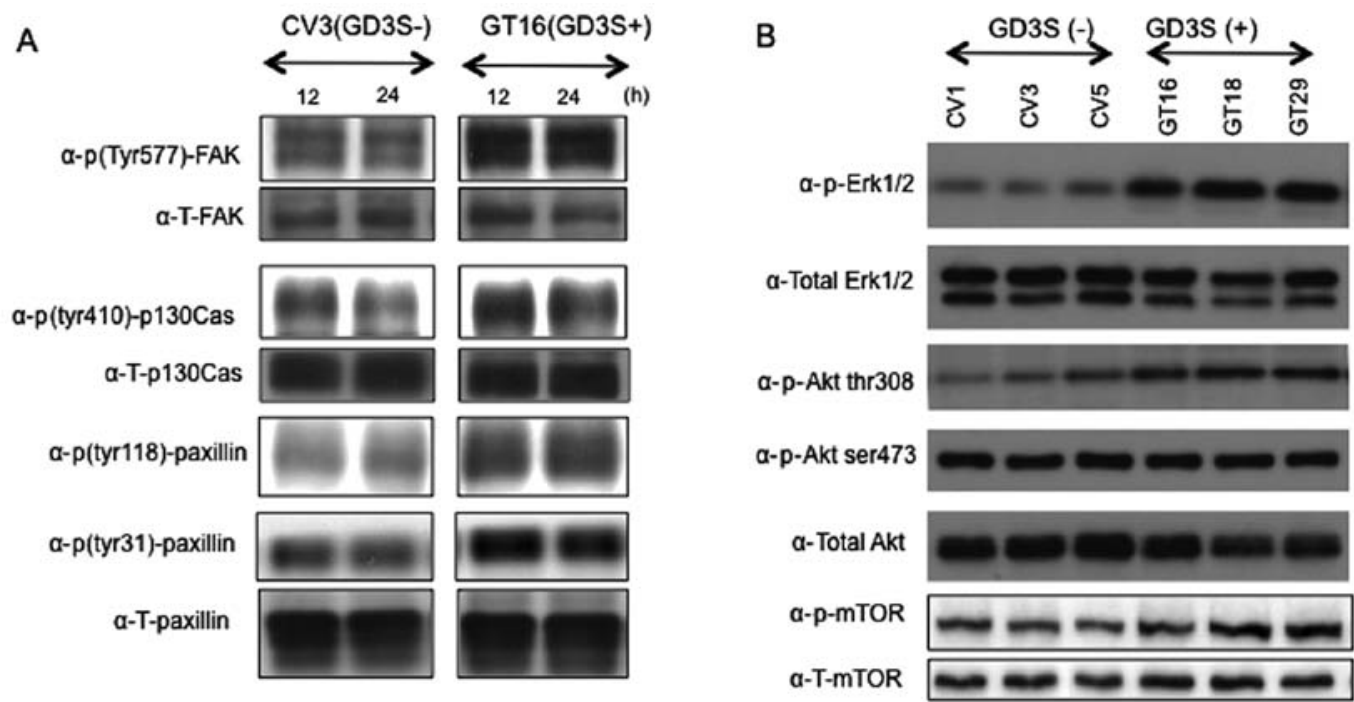

Figure 4. Increased phosphorylation levels of signaling molecules in GD3(+) transfectant cells. (A) Phosphorylation levels of focal adhesion kinase (FAK), paxillin and p130Cas were examined by western blot anlaysis using cells at 12 and $24 \mathrm{~h}$ after plating. Increased phosphorylation levels of FAK thr577, paxillin Tyr477 and p130Cas Tyr118 were observed. (B) Increased phosphorylation levels of Erk1/2 and Akt in cells cultured under standard conditions with serum. Western blot analysis of phospho-Erk1/2 phospho-Akt and phospho-mTOR was performed.
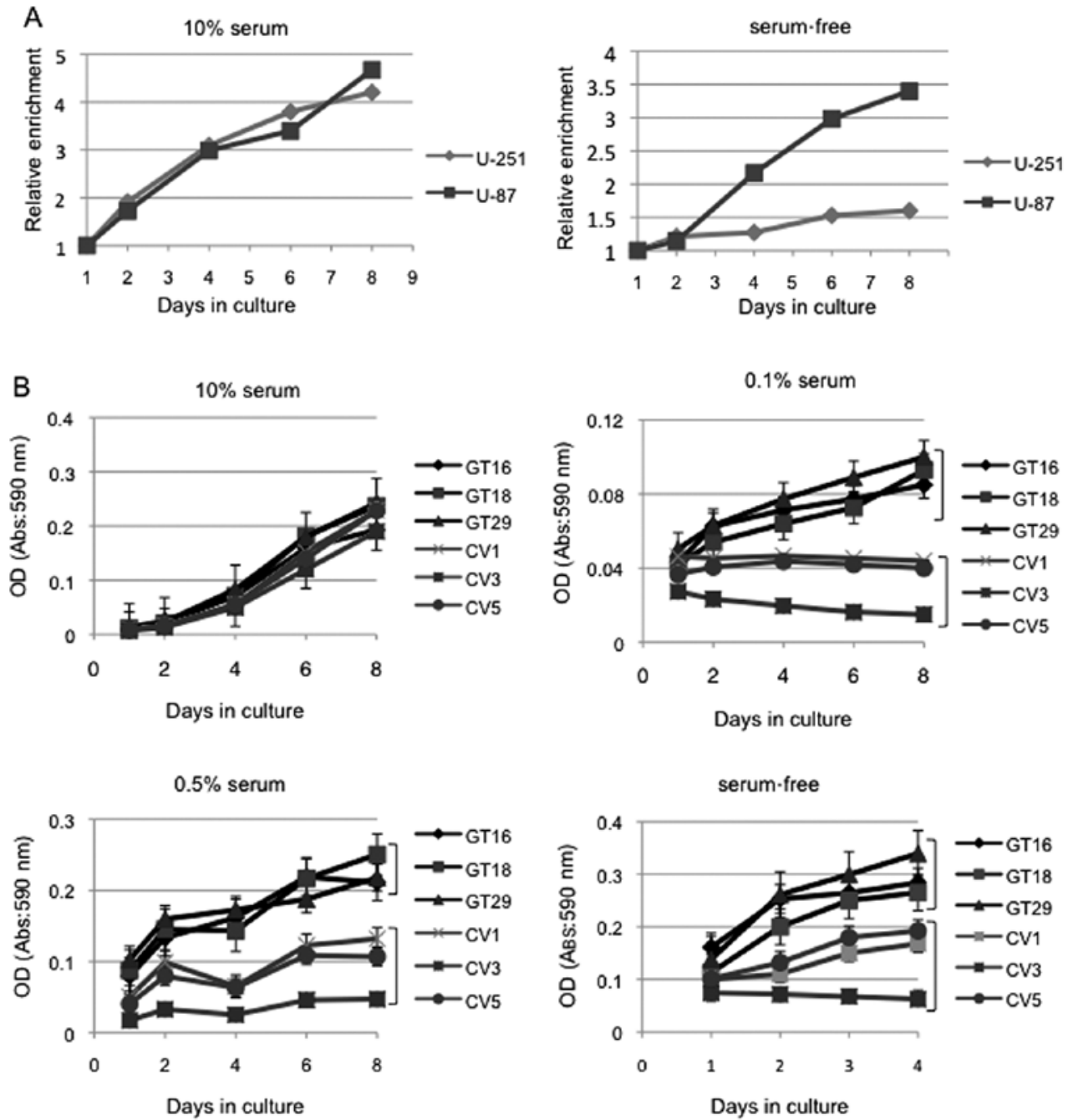

Figure 5. GD3(+) cells grew under no or low-serum conditions. (A) Comparison of cell growth under regular (left panel) or serum-free conditions (right panel) between two cell lines with high (U-87MG) or no expression (U-251MG) of GD3/GD2. MTT assay revealed that the U-87MG cells exhibited increased cell growth compared with the U-251MG cells under serum-free conditions. (B) Cell growth was compared by culturing U-251MG and its derivatives in medium containing $10,0.5,0.1$ or $0 \%$ serum. The results indicated that compared with the GD3(-) cells, the GD3(+) cells exhibited a greater cell growth when cultured under fetal calf serum (FCS) concentrations of $0-0.5 \%$. 
A

B
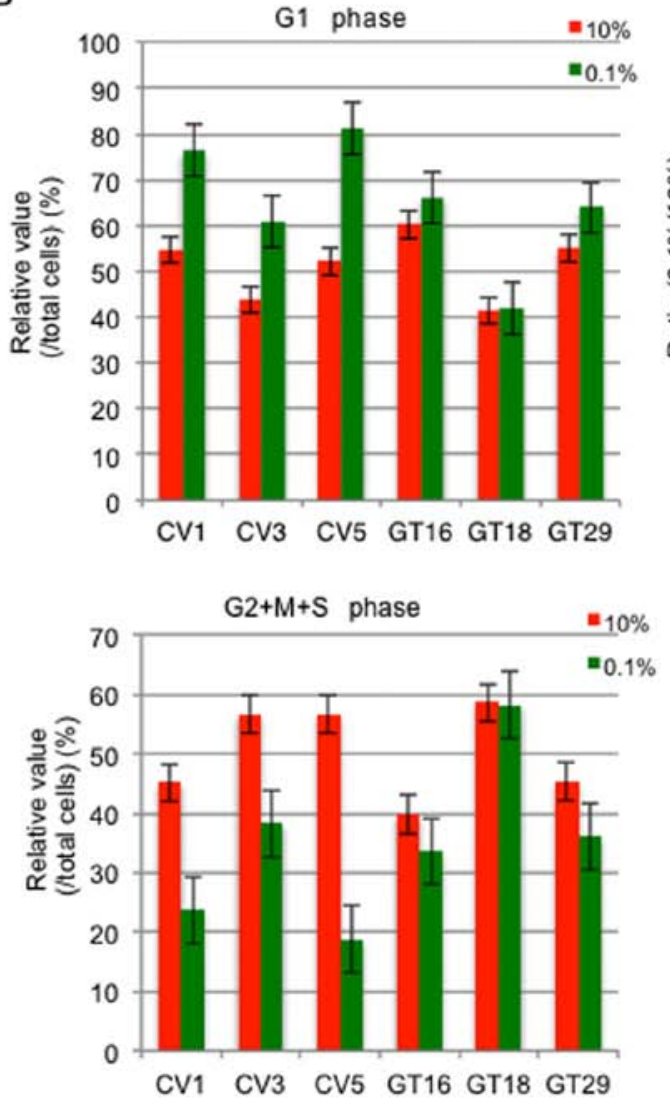
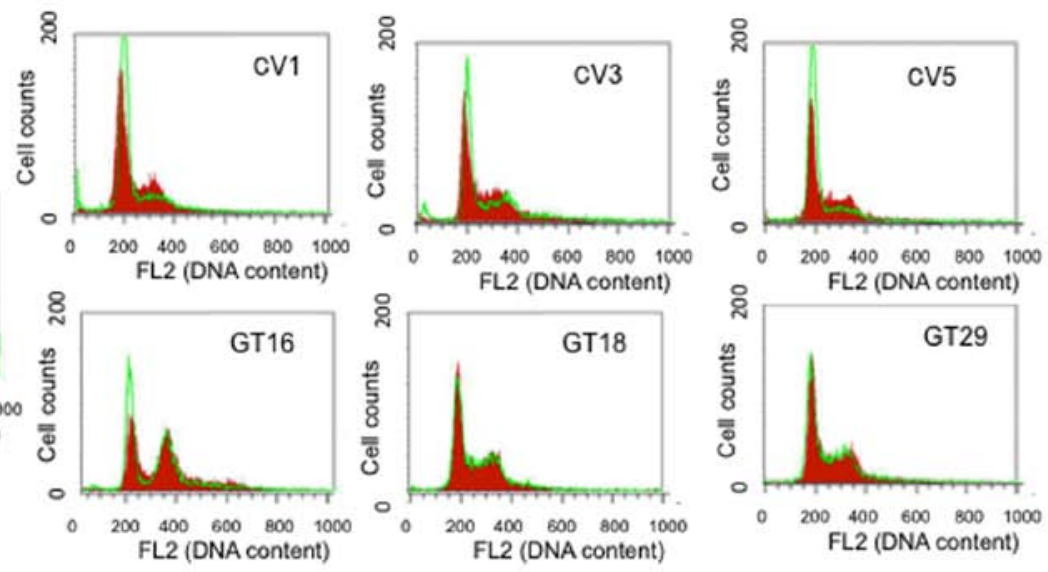
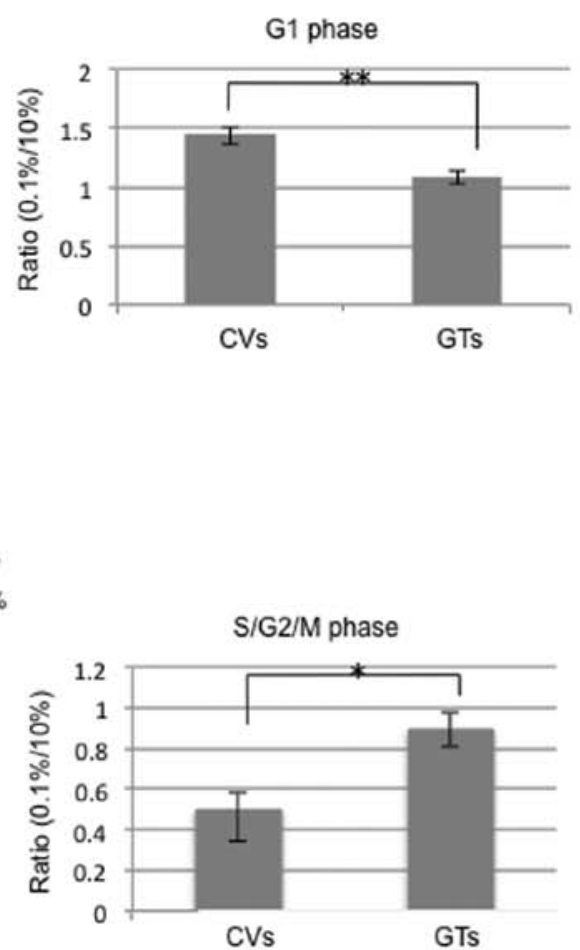

Figure 6. Comparison of cell cycle patterns between GD3(+) and GD3(-) cells. (A) Cell cycle patterns of GD3(+) cells and GD3(-) cells as analyzed by flow cytometry. Cells were prepared as described in the Materials and methods, and analyzed for DNA contents. Cells cultured with 10\% fetal calf serum (FCS) (red peaks) and those with 0.1\% FCS (green lines) were compared. (B) Summary of the cell cycle analysis. Ratios of cells at G1 phase (upper panel) and of cells at G2/M + S (bottom panel) of individual cells were shown comparing values with $10 \%$ FCS and $0.1 \%$ FCS (left panel). Ratios (0.1/10\%) in individual samples were calculated and average values of GD3(+) group and GD3(-) group were compared (right panel). Data are presented as the means \pm SD. Mean values were compared using an unpaired two-tailed Student's t-test. ${ }^{* *} \mathrm{P}<0.01$ and ${ }^{*} \mathrm{P}<0.05$.

compared with the U-251MG cells (Fig. 5A, right panel). Thus, the expression of GD3/GD2 seemed to be crucially involved in cell growth under serum-free conditions.

To further analyze this point, cell growth was compared by culturing the GD3(+) cells and GD3(-) cells in medium containing $10,0.5,0.1$ or $0 \%$ of serum. The results indicated that the GD3(+) cells had a definitely increased cell growth compared with the GD3(-) cells when cultured under FCS concentrations of $0.5,0.1$ and $0 \%$, while these cells showed no significant differences when cultured in medium with $10 \%$ FCS (Fig. 5B). These results suggested that GD3/GD2 expression confers the ability to cells to grow under conditions of reduced serum concentrations by modulating signaling molecules involved in cell growth.

Since the GD3(+) cells had significantly higher growth rates than the GD3(-) cells when cultured under conditions with $0.1 \%$ FCS, underlying mechanisms that are involved in the different growth under the condition with $0.1 \%$ FCS were investigated, focusing on apoptosis and the cell cycle. Consequently, no apoptosis was observed in both types of cells, as analyzed by 2-D flow cytometry with PI and FITC-Annexin V (data not shown). 


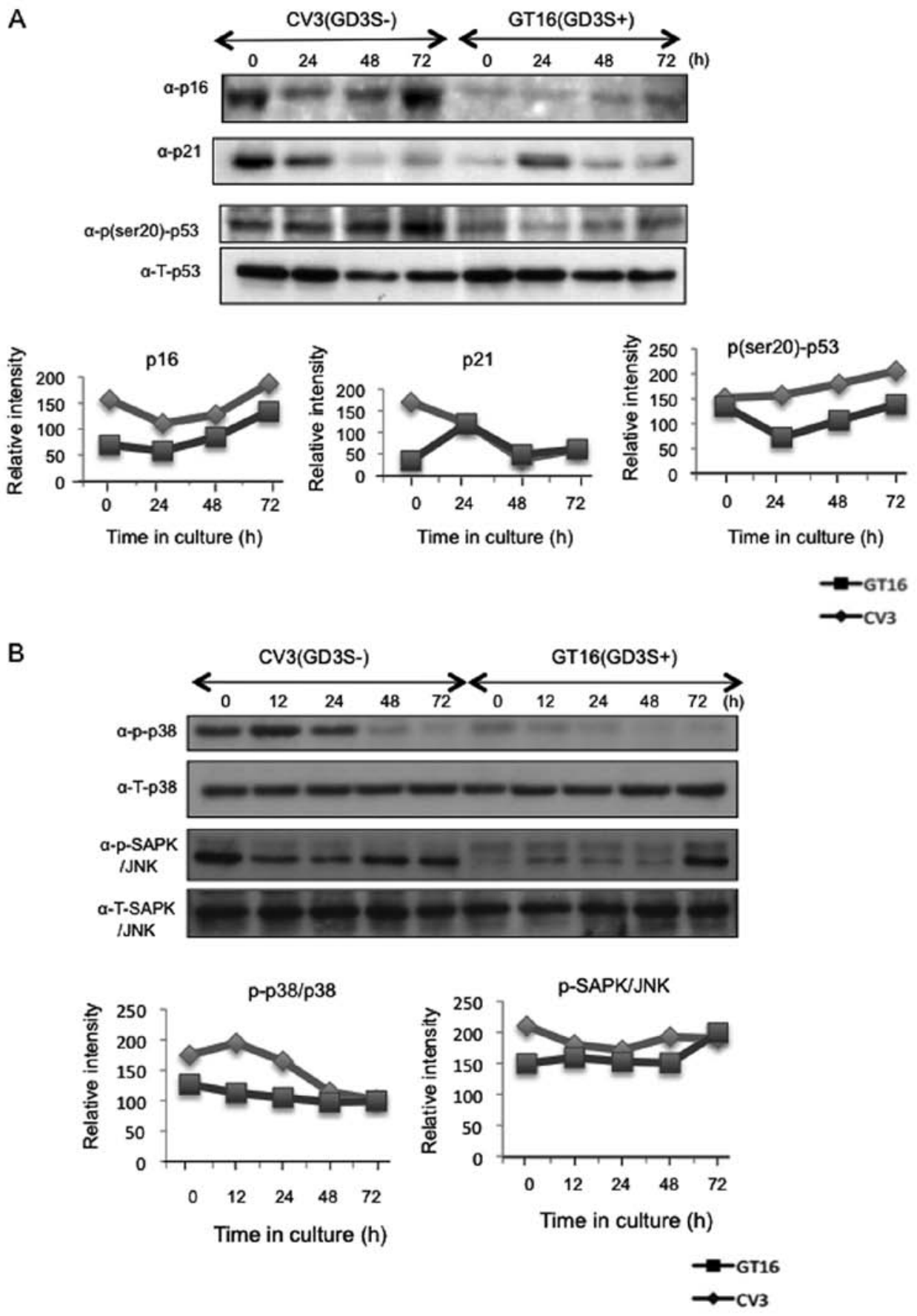

Figure 7. Expression of cell cycle-related proteins. (A) Expression levels of p16 and p21 were analyzed after serum removal. Phosphorylation of p53 (Ser20) was also examined by western blot analysis using a specific antibody. (B) Phosphorylation of p38 and SAPK/JNK was examined by western blot analysis at $0-72 \mathrm{~h}$ after serum deprivation from culture medium.

Cell cycle analysis under low serum conditions. Cell cycle distribution was analyzed, as shown in Fig. 6A. Cell cycle analysis revealed that the number of GD3(-) cells (CVs) in the G1 phase markedly increased as compared with the GD3(+) cells (GTs) when the serum concentration was reduced (Fig. 6). In turn, the numbers of GD3(-) cells in the G2/M and S phases markedly decreased, while the GD3(+) cells exhibited minimal changes (Fig. 6B). Of note, the GD3(-) cells seemed to stay mainly at the G1 phase under conditions with $0.1 \%$ FCS. These results corresponded with the results of MTT assay in which the GD3(-) cells exhibited a much slower growth rate than the GD3(+) cells under culture conditions with $0.1 \%$ FCS.
Expression of cell cycle-related proteins. Since the results of cell cycle analysis suggested that the GD3(-) cells arrested at the G1 phase when the serum concentration was reduced, the expression of $\mathrm{p} 16$ and $\mathrm{p} 21$, and the phosphorylation of $\mathrm{p} 53$ (Ser20) were analyzed by western blot analysis. Consequently, the induction and/or accumulation of p16 and p21 was found in the GD3(-) cells compared with the GD3(+) cells (Fig. 7A). Moreover, the phosphorylation of p53 (Ser20) was also increased in the GD3(-) cells. Taken together, the activation of p53 may have induced the accumulation of p16 and p21, leading to cell cycle arrest at the G1 phase in the GD3(-) cells. As for SAPK/JNK and p38, western blot analysis revealed 
A
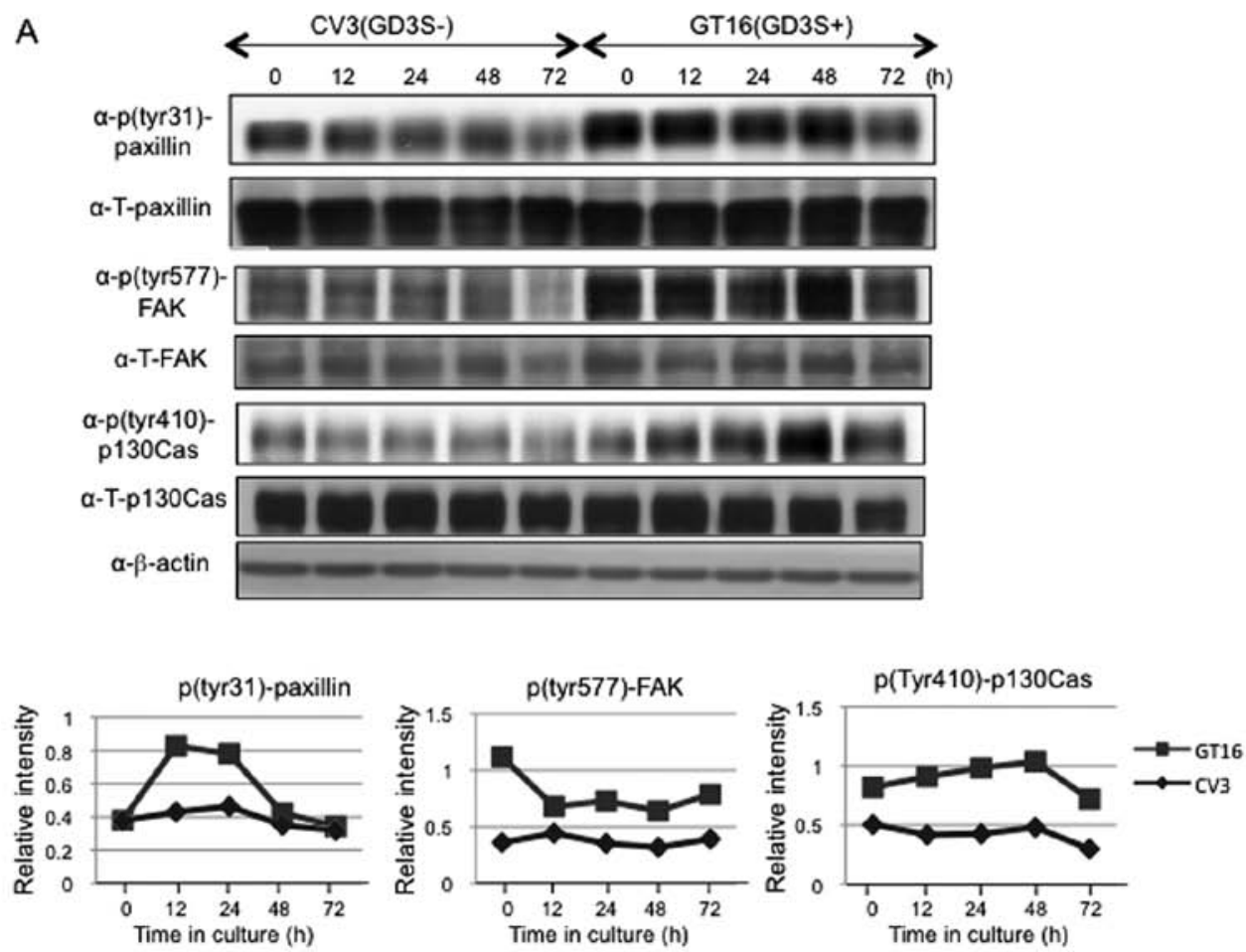

B

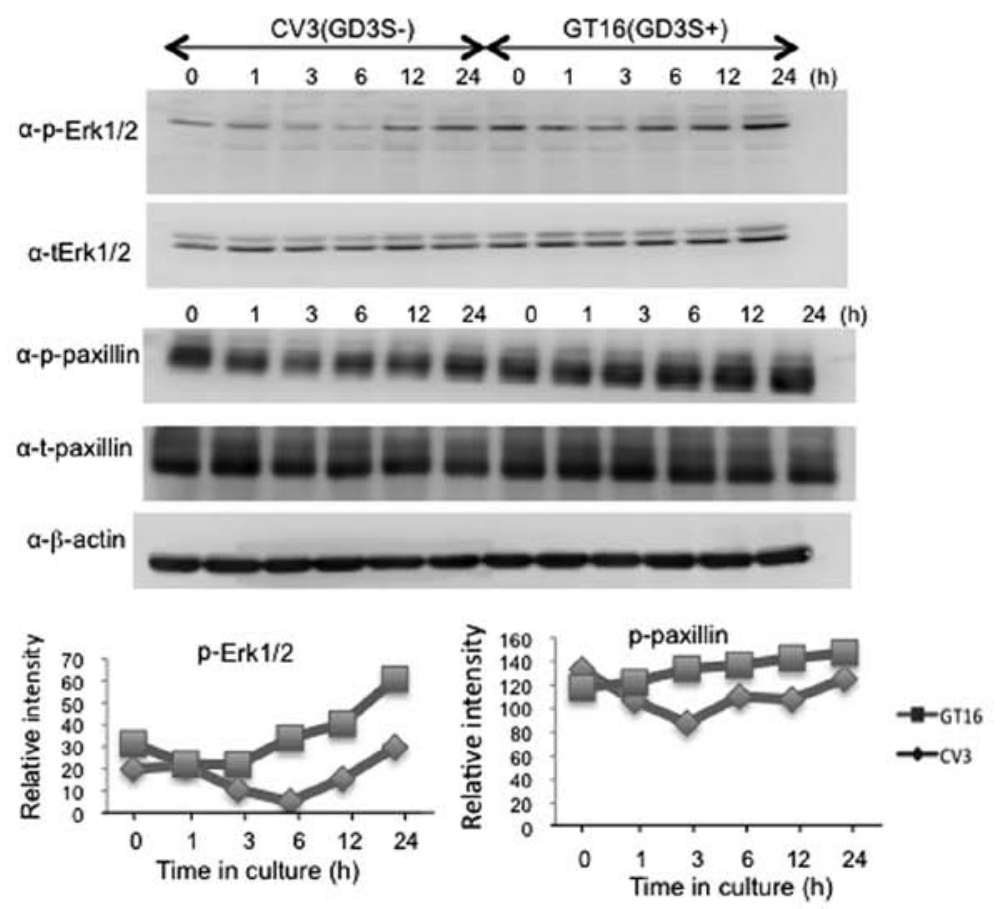

Figure 8. Higher phosphorylation levels of various signaling molecules in GD3(+) cells following serum deprivation. (A) Western blot analysis of p-Tyr31 paxillin, p-Tyr577 focal adhesion kinase (FAK) and p-Tyr410 p130Cas was performed using cells at $0-72 \mathrm{~h}$ after serum deprivation. Band intensities were scanned and presented after correction using those of individual total proteins. $\beta$-actin bands were shown to indicate equal loading. (B) Western blot analysis of phosphorylated Erk1/2 and paxillin at 0-24 h after serum deprivation with a fine time course. Band intensities were scanned and presented after correction using those of $\beta$-actin as described above.

that a stronger phosphorylation of $\mathrm{p} 38$ and SAPK/JNK was induced in the GD3(-) cells than in the GD3(+) cells (Fig. 7B).

The posphorylation levels of FAK, paxillin and p130Cas were fairly well maintained in the GD3(+) cells. By contrast, these levels showed a gradual reduction in the GD3(-) cells following serum removal, while they recovered $\sim 12-24 \mathrm{~h}$ after the reduction of serum (Fig. 8).

\section{Discussion}

One of the poor prognostic factors of gliomas, is the fact that glioma cells are characterized by an invasive behavior and ability to infiltrate into the surrounding normal tissues (37). Indeed, the border between tumor tissues and normal tissues is vague, thereby rendering the radical resection of tumors 
very difficult. In this study, it was clearly demonstrated that the U-251MG cells expressing high levels of GD3/GD2 exhibited increased invasion activity and enhanced motility. Furthermore, the elevation of the phosphorylation of Erk1/2 and Akt, and the increased phosphorylation levels of FAK, p130Cas and paxillin were observed. Thus, gangliosides GD3 and GD2 may be involved in the enhancement of the malignant properties of glioma cells, such as invasion and motility, as reported in malignant melanomas (35). In this study, their involvment in cell adhesion in gliomas was also clearly demonstrated in the RT-CES system (Fig. 3C).

The fact that the U-251MG cells expressing high levels of GD3 [GD3(+) cells] did not undergo cell cycle arrest, and proliferated even under no serum conditions suggested that rapidly growing cells become large in population, and GD3(+) tumor cells can overcome the difficulties in their survival, when competition between growth factors, nutrition and oxygen become severe among tumor cells. In this situation, GD3 and GD2 may be involved in the better adaptation of tumor cells to severe microenvironments.

First, GD3 and GD2 should assemble each other and form a cluster in glycolipid-enriched microdomains (GEM)/rafts (38). This may also recruit various membrane molecules, such as growth factor receptors and adhesion receptors to GEM/rafts, and modulate their functions to efficiently transduce cell signals to down-stream molecules and transcription factors (39-41). There have been a number of reports on the roles of GD3/GD2 in the enhancement of cell signaling mediated by epidermal growth factor receptor (42), TrkA (43), Met (21), integrins (44).

In melanomas, we have demonstrated that GD3 expression enhanced the activation levels of FAK, p130Cas and paxillin $(35,45)$, and adhesion signals via integrins is also required to induce the activation of these signaling molecules $(46,47)$. Moreover, we recently reported that the neogenin molecule is associated with GD3 on the cell surface of melanoma cells (48). $\gamma$-secretase is also recruited to GEM/rafts under GD3 expression, thereby cleaving intracytoplasmic region of neogenin to generate neogenin- intracytoplasmic domain (Ne-ICD). Intriguingly, $\mathrm{Ne}-\mathrm{ICD}$ appeared to play as a transcription factor by translocating into the nuclei and to promote expression of various target genes (48). Similar functions of GD3/GD2 may be also present to make glioma cells potentiated and grow better under culture condition with low serum concentration as shown in this study. Therefore, we should search ganglioside-associated molecules in glioma cells, too, and clarify roles of those molecules in the enhancement of malignant properties in gliomas by forming molecular complexes with GD3/GD2.

In recent studies, it has been shown that molecules located in the signaling pathway of receptor tyrosin kinases (RTKs)/RAS/PI3K frequently undergo genetic mutations, leading to ligand-independent activation of PTKs and the transduction of abnormal signals, and finally abnormal tumor growth and invasion into surrounding tissues $(49,50)$. In addition, the transcription factors AREB6 and Elk-1 are located at down-stream of RTK/RAS/PI3K signaling pathway, and both of these have been reported to positively regulate GD3 synthase gene (51). Thus, it may be possible that GD3/GD2 highly expressed in glioma tissues recruit mutated RTKs to GEM/rafts, and activate RTKs in a ligand-independent manner, leading to the increased malignant properties of gliomas. On the other hand, activated AREB6 and Elk-1 by RTK/RAS/PI3K signals may enhance expression of GD3/GD2 by forming a positive feed back loop (51).

Gliomas are generally resistant to current chemotherapy and radiation therapy. Therefore, it is necessary to develop novel approaches in which cancer cells can be selectively destroyed without damage to normal tissues. Therefore, GD3/GD2 and their associating molecules on the cell surface may be promising targets in the construction of therapeutic strategy for patients with glioma. However, this study has limitations due to in vitro analysis. Therefore, we have performed animal experiments, and some of these results have already already published (29); Further studies using mouse gliomas generated in GD3 synthase-lacking mice are ongoing. As for clinical analysis, we aim to carry out studies using materials from patients with glioma. Thus, supportive results for our conclusions reported herein will be obtained in the near future.

\section{Acknowledgements}

The authors would like to thank Mrs. T. Mizuno, Mrs. Y. Nakayasu (at Nagoya University) and Mrs. S. Yamamoto (at Chubu University) for providing technical assistance.

\section{Funding}

This study was supported by Grants-in-Aid from the Ministry of Education, Culture, Sports and Technology of Japan (MEXT) (15H04696, 15K15080).

\section{Availability of data and materials}

The analyzed data sets generated during the study are available from the corresponding author on reasonable request.

\section{Authors' contributions}

TI, PZ, YO and YO performed the biochemical and cell biology experiments. HM, RHB and TW performed the immunohistochemistry experiments. RHB and KeF performed the cell cycle analysis. $\mathrm{HM}, \mathrm{KeF}$ and $\mathrm{KoF}$ designed the experiments, and $\mathrm{TI}, \mathrm{KeF}$ and $\mathrm{KoF}$ wrote the manuscript.

\section{Ethics approval and consent to participate}

Brain tumor samples were obtained for use in the experiments after obtaining informed consent. This study was performed in accordance with the code of Ethics of the World Medical Association, and approved by the Ethics Committee of Nagoya University Graduate School of Medicine, Nagoya, Japan.

\section{Consent for publication}

Not applicable.

\section{Competing interests}

The authors declare that they have no competing interests. 


\section{References}

1. Greene LA, Lee HY and Angelastro JM: The transcription factor ATF5: Role in neurodevelopment and neural tumors. J Neurochem 108: 11-22, 2009.

2. Schiffer D, Annovazzi L, Caldera V and Mellai M: On the origin and growth of gliomas. Anticancer Res 30: 1977-1998, 2010.

3. Huse JT and Holland EC: Targeting brain cancer: Advances in the molecular pathology of malignant glioma and medulloblastoma. Nat Rev Cancer 10: 319-331, 2010.

4. Zong H, Verhaak RG and Canoll P: The cellular origin for malignant glioma and prospects for clinical advancements Expert Rev Mol Diagn 12: 383-394, 2012.

5. Xie Q, Mittal S and Berens ME: Targeting adaptive glioblastoma: An overview of proliferation and invasion. Neuro Oncol 16: $1575-1584,2014$

6. Woehrer A, Bauchet L and Barnholtz-Sloan JS: Glioblastoma survival: Has it improved? Evidence from population-based studies. Curr Opin Neurol 27: 666-674, 2014

7. Wiegandt H: Gangliosides. In: Glycolipids. Wiegandt H (ed). Vol 10. Elsevier Science Publishers, Amsterdam, pp199-260, 1985.

8. Yu RK, Bieberich E, Xia T and Zeng G: Regulation of ganglioside biosynthesis in the nervous system. J Lipid Res 45: 783-793, 2004.

9. Schengrund CL: Gangliosides: Glycosphingolipids essential for normal neural development and function. Trends Biochem Sci 40: 397-406, 2015.

10. Yates AJ: Gangliosides in the nervous system during development and regeneration. Neurochem Pathol 5: 309-329, 1986.

11. Hakomori S: Philip Levine award lecture: Blood group glycolipid antigens and their modifications as human cancer antigens. Am J Clin Pathol 82: 635-648, 1984

12. Lloyd KO: Humoral immune responses to tumor-associated carbohydrate antigens. Semin Cancer Biol 2: 421-431, 1991.

13. Schulz G, Cheresh DA, Varki NM, Yu A, Staffileno LK and Reisfeld RA: Detection of ganglioside GD2 in tumor tissues and sera of neuroblastoma patients. Cancer Res 44: 5914-5920, 1984.

14. Saito M, Yu RK and Cheung NK: Ganglioside GD2 specificity of monoclonal antibodies to human neuroblastoma cell. Biochem Biophys Res Commun 127: 1-7, 1985.

15. Merritt WD, Casper JT, Lauer SJ and Reaman GH: Expression of GD3 ganglioside in childhood T-cell lymphoblastic malig nancies. Cancer Res 47: 1724-1730, 1987.

16. Siddiqui B, Buehler J, DeGregorio MW and Macher BA Differential expression of ganglioside GD3 by human leukocytes and leukemia cells. Cancer Res 44: 5262-5265, 1984.

17. Cheresh DA, Rosenberg J, Mujoo K, Hirschowitz L and Reisfeld RA: Biosynthesis and expression of the disialoganglioside GD2, a relevant target antigen on small cell lung carcinoma for monoclonal antibody-mediated cytolysis. Cancer Res 46: 5112-5118, 1986.

18. Yoshida S, Fukumoto S, Kawaguchi H, Sato S, Ueda R, Furukawa K and Ganglioside G: Ganglioside G(D2) in small cell lung cancer cell lines: Enhancement of cell proliferation and mediation of apoptosis. Cancer Res 61: 4244-4252, 2001.

19. Azuma K, Tanaka M, Uekita T, Inoue S, Yokota J, Ouchi Y and Sakai R: Tyrosine phosphorylation of paxillin affects the metastatic potential of human osteosarcoma. Oncogene 24 : 4754-4764, 2005.

20. Shibuya H, Hamamura K, Hotta H, Matsumoto Y, Nishida Y, Hattori H, Furukawa K, Ueda M and Furukawa K: Enhancement of malignant properties of human osteosarcoma cells with disialyl gangliosides GD2/GD3. Cancer Sci 103: 1656-1664, 2012.

21. Cazet A, Bobowski M, Rombouts Y, Lefebvre J, Steenackers A, Popa I, Guérardel Y, Le Bourhis X, Tulasne D and Delannoy P: The ganglioside G(D2) induces the constitutive activation of c-Met in MDA-MB-231 breast cancer cells expressing the G(D3) synthase. Glycobiology 22: 806-816, 2012.

22. Furukawa K, Akagi T, Nagata Y, Yamada Y, Shimotohno K, Cheung NK, Shiku H and Furukawa K: GD2 ganglioside on human T-lymphotropic virus type I-infected T cells: Possible activation of beta-1,4-N-acetylgalactosaminyltransferase gene by p40tax. Proc Natl Acad Sci USA 90: 1972-1976, 1993.

23. Fredman P, von Holst H, Collins VP, Ammar A, Dellheden B, Wahren B, Granholm L and Svennerholm L: Potential ganglioside antigens associated with human gliomas. Neurol Res 8: 123-126, 1986.
24. Wikstrand CJ, Fredman P, Svennerholm L and Bigner DD Detection of glioma-associated gangliosides GM2, GD2, GD3, 3'-isoLM1 3',6'-isoLD1 in central nervous system tumors in vitro and in vivo using epitope-defined monoclonal antibodies. Prog Brain Res 101: 213-223, 1994

25. Gaini SM, Riboni L, Cerri C, Grimoldi N, Sganzerla EP and Berra B: Ganglioside content and composition in human gliomas. Acta Neurochir Suppl (Wien) 43: 126-129, 1988

26. Kawai K, Takahashi H, Watarai S, Ishizu H, Fukai K, Tanabe Y, Nose S and Kuroda S: Occurrence of ganglioside GD3 in neoplastic astrocytes. An immunocytochemical study in humans. Virchows Arch 434: 201-205, 1999.

27. Wagener R, Röhn G, Schillinger G, Schröder R, Kobbe B and Ernestus RI: Ganglioside profiles in human gliomas: Quantification by microbore high performance liquid chromatography and correlation to histomorphology and grading. Acta Neurochir (Wien) 141: 1339-1345, 1999.

28. Vukelić Z, Kalanj-Bognar S, Froesch M, Bîndila L, Radić B, Allen M, Peter-Katalinić J and Zamfir AD: Human gliosarcomaassociated ganglioside composition is complex and distinctive as evidenced by high-performance mass spectrometric determination and structural characterization. Glycobiology 17: 504-515, 2007.

29. Ohkawa Y, Momota H, Kato A, Hashimoto N, Tsuda Y, Kotani N, Honke K, Suzumura A, Furukawa K, Ohmi Y, et al: Ganglioside GD3 enhances invasiveness via Yes activation by forming a complex of GD3/PDGFR $\alpha /$ Yes in gliomas. J Biol Chem 290: 16043-16058, 2015.

30. Svennerholm L: Chromatographic separation of human brain gangliosides. J Neurochem 10: 613-623, 1963

31. Zhao J, Furukawa K, Fukumoto S, Okada M, Miyazaki H, Shiku H, Aizawa S, Matsuyama M, Furukawa K: Attenuation of the interleukin 2 signals in complex ganglioside-lacking mice. J Biol Chem 274: 13744-13747, 1999.

32. Allen M, Bjerke M, Edlund H, Nelander S and Westermark B: Origin of the U87MG glioma cell line: Good news and bad news. Sci Transl Med 8: 354re3, 2016.

33. Bady P, Diserens AC, Castella V, Kalt S, Heinimann K, Hamou MF, Delorenzi M and Hegi ME: DNA fingerprinting of glioma cell lines and considerations on similarity measurements. Neuro Oncol 14: 701-711, 2012.

34. Haraguchi M, Yamashiro S, Yamamoto A, Furukawa K, Takamiya K, Lloyd KO, Shiku $\mathrm{H}$ and Furukawa K: Isolation of GD3 synthase gene by expression cloning of GM3 alpha-2,8-sialyltransferase cDNA using anti-GD2 monoclonal antibody. Proc Natl Acad Sci USA 91: 10455-10459, 1994.

35. Hamamura K, Furukawa K, Hayashi T, Hattori T, Nakano J, Nakashima H, Okuda T, Mizutani H, Hattori H, Ueda M, et al: Ganglioside GD3 promotes cell growth and invasion through p130Cas and paxillin in malignant melanoma cells. Proc Natl Acad Sci USA 102: 11041-11046, 2005.

36. Aixinjueluo W, Furukawa K, Zhang Q, Hamamura K, Tokuda N, Yoshida S, Ueda R and Furukawa K: Mechanisms for the apoptosis of small cell lung cancer cells induced by anti-GD2 monoclonal antibodies: Roles of anoikis. J Biol Chem 280: 29828-29836, 2005.

37. Rao JS: Molecular mechanisms of glioma invasiveness: The role of proteases. Nat Rev Cancer 3: 489-501, 2003.

38. Hakomori SI: Cell adhesion/recognition and signal transduction through glycosphingolipid microdomain. Glycoconj J 17: 143-151, 2000.

39. Kim OS, Park EJ, Joe EH and Jou I: JAK-STAT signaling mediates gangliosides-induced inflammatory responses in brain microglial cells. J Biol Chem 277: 40594-40601, 2002.

40. Gabellini N, Facci L, Milani D, Negro A, Callegaro L, Skaper SD and Leon A: Differences in induction of $\mathrm{c}$-fos transcription by cholera toxin-derived cyclic AMP and $\mathrm{Ca}^{2+}$ signals in astrocytes and 3T3 fibroblasts. Exp Cell Res 194: 210-217, 1991.

41. Song N, Kim SJ, Kwon HY, Son SW, Kim KS, Ahn HB and Lee YC: Transcriptional activation of human GM3 synthase (hST3Gal V) gene by valproic acid in ARPE-19 human retinal pigment epithelial cells. BMB Rep 44: 405-409, 2011.

42. Wang J and Yu RK: Interaction of ganglioside GD3 with an EGF receptor sustains the self-renewal ability of mouse neural stem cells in vitro. Proc Natl Acad Sci USA 110: 19137-19142, 2013.

43. Fukumoto S, Mutoh T, Hasegawa T, Miyazaki H, Okada M, Goto G, Furukawa K, Urano T and Furukawa K: GD3 synthase gene expression in $\mathrm{PC} 12$ cells results in the continuous activation of TrkA and ERK1/2 and enhanced proliferation. J Biol Chem 275: 5832-5838, 2000. 
44. Ohkawa Y, Miyazaki S, Miyata M, Hamamura K, Furukawa K and Furukawa K: Essential roles of integrin-mediated signaling for the enhancement of malignant properties of melanomas based on the expression of GD3. Biochem Biophys Res Commun 373: 14-19, 2008.

45. Hamamura K, Tsuji M, Ohkawa Y, Nakashima H, Miyazaki S, Urano T, Yamamoto N, Ueda M, Furukawa K and Furukawa K: Focal adhesion kinase as well as p130Cas and paxillin is crucially involved in the enhanced malignant properties under expression of ganglioside GD3 in melanoma cells. Biochim Biophys Acta 1780: 513-519, 2008.

46. Valentino LA and Ladisch S: Tumor gangliosides enhance alpha2 beta1 integrin-dependent platelet activation. Biochim Biophys Acta 1316: 19-28, 1996.

47. Ohkawa Y, Miyazaki S, Hamamura K, Kambe M, Miyata M, Tajima O, Ohmi Y, Yamauchi Y, Furukawa K and Furukawa K: Ganglioside GD3 enhances adhesion signals and augments malignant properties of melanoma cells by recruiting integrins to glycolipid-enriched microdomains. J Biol Chem 285: 27213-27223, 2010.
48. Kaneko K, Ohkawa Y,Hashimoto N, Ohmi Y,Kotani N, Honke K, Ogawa M, Okajima T, Furukawa K and Furukawa K: Neogenin defined as a GD3-associated molecule by enzyme-mediated activation of radical sources confers malignant properties via intra-cytoplasmic domain in melanoma cells. J Biol Chem 291: 16630-16643, 2016.

49. Guo G, Gong K, Wohlfeld B, Hatanpaa KJ, Zhao D and Habib AA: Ligand-independent EGFR signaling. Cancer Res 75: 3436-3441, 2015.

50. Comoglio PM, Boccaccio C and Trusolino L: Interactions between growth factor receptors and adhesion molecules: Breaking the rules. Curr Opin Cell Biol 15: 565-571, 2003.

51. Dae HM, Kwon HY, Kang NY, Song NR, Kim KS, Kim CH, Lee $\mathrm{JH}$ and Lee YC: Isolation and functional analysis of the human glioblastoma-specific promoter region of the human GD3 synthase (hST8Sia I) gene. Acta Biochim Biophys Sin (Shanghai) 41: 237-245, 2009. 